\title{
A Training Program in Food Safety in Lebanon
}

\section{Adel Cortas*}

Former Minister of Agriculture, President of the Association of the Water Friends in Lebanon, Lebanon

\section{Impact on the Economy of Food Safety}

Food safety has an impact on the national economy and public health. The food industry makes up most of the factories in Lebanon (18.2\%), involves about $25 \%$ of the total labor force and produces the number one of its exports (around 1.7 billion dollars. Despite all this Food Safety is still a major issue in Lebanon.

\section{Purpose of the Paper}

The main purpose of this paper is to define and spell out the elements of a training program in food safety in Lebanon.

This would be the main task of the FSLC (Food Safety of the Lebanese Commission) under articles 22-23 of the Food Safety Law, approved by the Lebanese Parliament, on 24 October 2016 [1]. Unfortunately, this Commission was not yet established. It is hoped that this paper would be considered as the guideline to the Commission on what should be done in Food Safety Training.

The first task of the Commission is to sit down with the representatives of the nine government agencies in the respective ministries and those independent and discuss with them problems related to Food Safety in Lebanon and draw programs and define policies and what should be done. In fact before the publication of the New Food Safety Law, all these agencies were dealing with Food Safety in one way on the other. But there were no coordination among them whatsoever. In this sense the FSLC will fill this gap in the future. Its main task is to look and see what is being done in each agency/ ministry and see that there is no duplication with another agency/ ministry.

The Ministry of Agriculture is dealing with regulations related to production and marketing of agricultural crops and animal products, their handling, grading systems, until reaching the consumers [2]. In this respect the Ministry had started and should continue implementing the project of GAP (Good Agricultural Practices) of production and marketing until reaching the consumers.

The Ministry of Economy and Trade where the department of the consumer protection is responsible of the rules and regulations pertaining to the implementation of the law related to the protection of the consumer. However, the Ministry was never able of covering all the problems related to food safety.

The Ministry of Public Health, relatively speaking was doing a little bit better.

LIBNOR (the Lebanese Norms Organizations) located at the Ministry of Industry cooperated with other administrations was doing better, but was never able to cover all agricultural commodities and food products in Lebanon. The Ministry of Environment although had good ministers since its inception, but problems of food safety were of minor priority to the Ministry.

The Ministry of Social Affairs did not have any priority to problems of food safety.

\section{Publication History:}

Received: May 30, 2018

Accepted: June 20, 2018

Published: June 22, 2018

\section{Keywords:}

Foof safety, Lebanese food industries, Lebanese government, Food laboratories, Agriculture

The municipalities which cover the whole territory of Lebanon, which is good advantage because they are in contact with many of food safety users; but they were never interested in this field and they never tried to be responsible in this area.

As we can see these, rules and regulations on food safety in many ministries and organizations, unfortunately there was no coordination among them, and there was no system on a policy on food safety.

The first task of FSLC will aim at preparing a proposed program on what should be done by the Lebanese government in order to reach a better level in Food Safety conditions. A detailed analysis is made of these articles and confronts them with the work done by assisting the nine agencies dealing with food safety in Lebanon. The problem is that so far, we don't have a program or a policy dealing with food safety in Lebanon.

The second task for FSLC is to put its house in order by preparing and drafting the resolution to be submitted to the Council of Ministers covering:

1. The bye-laws of FSLC

2. The description of terms of reference of its staff

3. The financial regulations pertaining to FSLC and income which will be from the state budget or borrowing from the Treasury for activities held by FSLC proper or gifts from others.

All this covered under article 28 of the Food Safety Law.

The third task for FSLC, under article 29 is to prepare the Strategy on Food Safety of Lebanon. In other words the task for FSLC is to define the system on food safety and prepare the program or food policy in Lebanon in cooperation with representatives from the nine agencies. A Food Safety System will be established.

"Corresponding Author: Dr. Adel Cortas, Former Minister of Agriculture, President of the Association of the Water Friends in Lebanon; E-mail: acortas@dm.net.lb

Citation: Cortas A (2018) A Training Program in Food Safety in Lebanon. Int J Clin Nutr Diet 4: 130. doi: https://doi.org/10.15344/2456-8171/2018/130

Copyright: (C) 2018 Cortas. This is an open-access article distributed under the terms of the Creative Commons Attribution License, which permits unrestricted use, distribution, and reproduction in any medium, provided the original author and source are credited. 
Page 2 of 3

The system should cover

1. Production of food

2. Processing

3. Packing and labelling

4. Importing

5. Distribution

6. Retailing

7. Catering

Food inspection, the universities and the public in Lebanon, should be aware of all those problems as they should be aware of the needs for regulations covering:

1. Food premises registration

2. Food composition and labelling

3. Food diseases

4. Food poisoning

5. Food hygiene

6. Food complaints

7. Advice for catering of food sold unpackaged food inspection regulations should be well publicized at the producers, retailers and consumers as well.

\section{The Present Food Safety System}

Before the publication of the new law and approval by the parliament of the new law on Food Safety, there were nine agencies dealing with Food Safety. The following figure shows the names of these agencies.
These programs are pertaining to:

1. To the protection of public health by strengthening the Food Safety System and control standards to improve Food Safety only to the extent that producers and processors comply with them.

2. How to define the regulations for the enforcement of Food Standards regulations, safety and hygiene?

3. There is still a way for the improvement of the food inspectors capacities at the Ministries of the Agriculture, Public Health and Economy and Trade for better.

\section{The Other Major Task of the FSL}

The final task of FSLC is to look into more details into the problems of education and training of professionals dealing with food safety in Lebanon. We pride ourselves in Lebanon, for the number of universities we have. However, the number of universities dealing with agricultural education and research will not be exceed five universities and those dealing with nutrition and food safety are the American University of Beirut (AUB), Lebanese American University (LAU), and to some extent the holy spirit (Kaslik) University. Some incentives should be given to the other three universities teaching Agriculture in Lebanon to do some research and give courses dealing with Food Safety and nutrition.

A continuous training program should be A continuous training program should be scheduled, annually, between FSLC and representatives of the nine agencies, in cooperation with the universities teaching Nutrition and Food Safety. LAU, within its Food Safety program is giving annually a course with a certificate in Food Safety. This certificate was highly appreciated by the Syndicate of the Lebanese Food Industries (SLFI) and the General Union of Arab Chambers of Commerce. They were willing to pay higher salaries for those having the certificate on Food Safety Training.

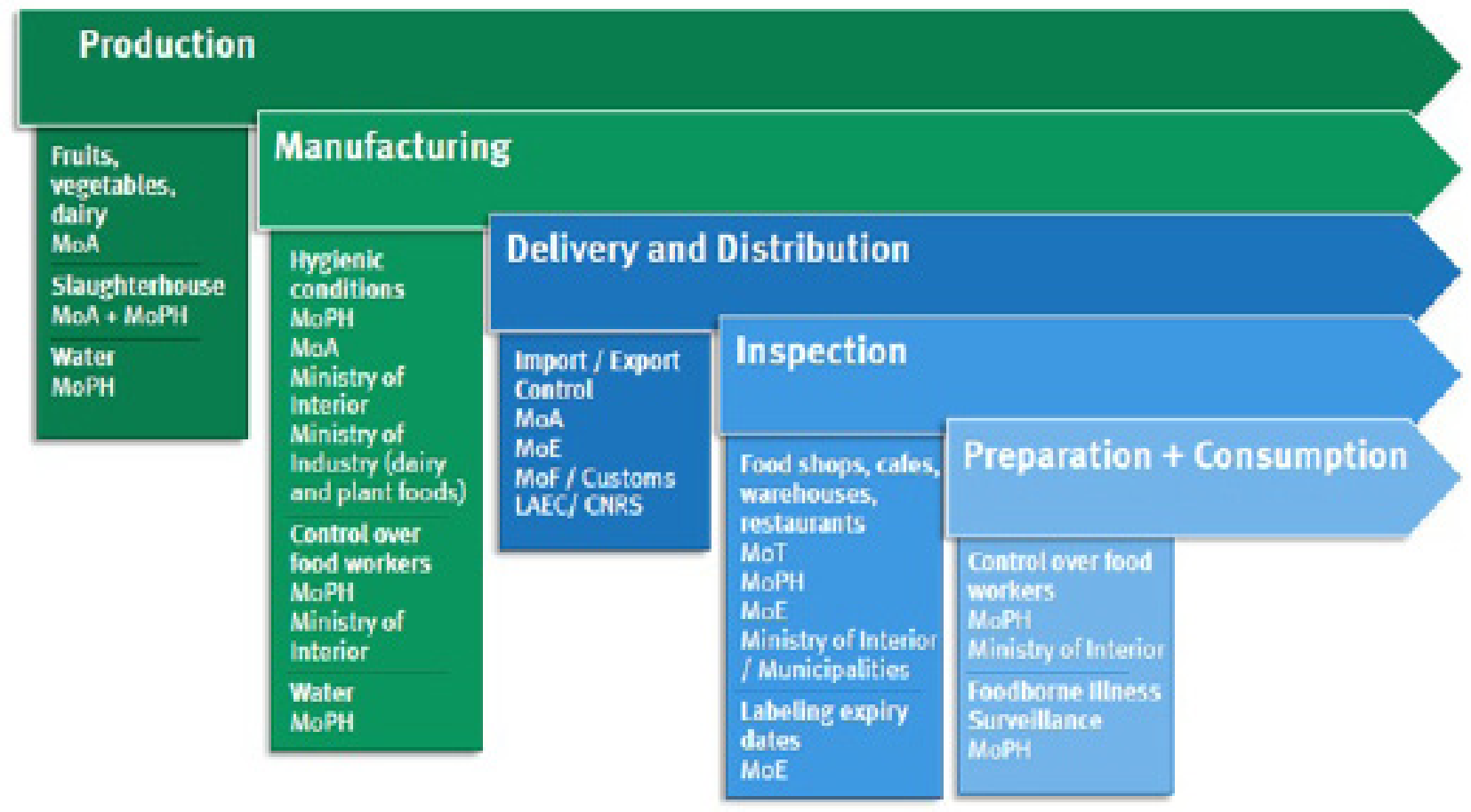

Figure 1: Stakeholders in the Lebanese Food chain. 


\section{Conclusions and Recommendations}

The success of the New Food Safety law depends on how it will be implemented. A campaign should immediately be launched, now that the law is enacted, to draw attention to its importance and added value to Lebanese citizens.

Just recently the FSLC Chief was appointed by the Council of Ministers of Lebanon. This is good news for the Lebanese community. I propose that a workshop be organized and held by the Government of Lebanon in cooperation with FAO and WHO representations in Lebanon [5]. All the nine agencies mentioned in this paper and universities will be invited to attend and brief the new FSLC Chief on projects to be implemented of Food Safety in Lebanon.

A major task for FSLC is to impose its respect to the nine agencies in the ministries dealing with food safety and have good cooperation between the two sites.

We don't need new laws and regulations concerning food safety as we need better trained people to implement them. The major task, is in the area of inspectors, almost everywhere FSLC should have its own team of well-trained inspectors, to fill the gap of the ministries.

Well organized meeting under the leadership of FSLC should be establishing regularly to discuss problems and find solutions.

All this training program for Food Safety should be supplemented by another program of accreditations, for new laboratories should be initiated by FSLC, to help and assist the existing ones at the ministry of agriculture in Fanar.

Food laboratories have a major role in food accreditation for the purpose of better Food Safety. At present the food authorities in Lebanon rely on the Food Safety Research Institute at Fanar (Beirut Suburbs), the Laboratories of the Industrial Research Institute and the Laboratories of AUB to ensure about the qualities for food produced in Lebanon or imported from abroad [3]. The Fanar Laboratories originally were established by an FAO Project under the authority of the Ministry of Agriculture [4].

\section{Competing Interests}

The authors declare that no competing interests is present.

\section{References}

1. The full text of the Food Safety Law in Lebanon, which was approved by Parliament on 24 October 2016, under the number 35.

2. Annahar newspaper in Arabic.

3. The article of AUB Faculty of Health Sciences on Protecting the Consumers in Lebanon.

4. The FAO Program in Lebanon.

5. Strategy of agricultural development. The Ministry of Agriculture in cooperation with FAO. 